\title{
Influência das variáveis envolvidas no plantio de arroz nas características da cinza de casca de arroz
}

Influence of the variables involved in the planting of rice in the rice husk ash's characteristics

\section{Everton José da Silva \\ Jorge Luís Akasaki Jean Richard Dasnoy}

Everton José da Silva Departamento de Engenharia Civil, Faculdade de Engenharia de Itha Solteira Universidade Estadual Paulista Avenida Brasil, 56, Centro Ilha Solteira - SP - Brasil CEP 15385-000

Tel.: (18) 3743-1077 Email:

Jorge Luís Akasaki Departamento de Engenharia Civil, Faculdade de Engenharia de Ilha Solteira Universidade Estadual Paulista Júlio de Mesquita Filho Alameda Bahia, 550, Centro Itha Solteira - SP - Brasil CEP 15385-000 Tel.: (18)3743-1213

Jean Richard Dasnoy Departamento de Física e Química Universidade Estadual Paulista Júlio de Mesquita Filho Avenida Brasil, 56, Centro Caixa-Postal 31 Ilha Solteira - SP - Brasil CEP 15385-000 Tel.: (18) 763-8163

Recebido em 11/04/09 Aceito em 24/05/09

\section{Resumo}

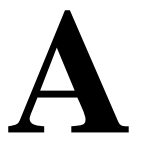

produção de arroz no Brasil em 2008 foi de aproximadamente 12 milhões de toneladas e para atingir essa quantidade são utilizadas diversas técnicas de plantio e diferentes cultivares nas distintas regiões onde o arroz é cultivado. Como a cinza de casca de arroz (CCA) é a pozolana de origem vegetal mais estudada pelos pesquisadores que trabalham na área de materiais pozolânicos, o presente trabalho compreende uma análise da influência que a forma de plantio, clima, solo, cultivares e fonte/quantidade de fertilizantes à base de nitrogênio utilizados na cultura do arroz exercem na composição química e propriedades cristalográficas da CCA. De acordo com os resultados obtidos neste trabalho, verifica-se a importância de se fazer ensaios rotineiros de análises químicas e de Difração de Raio-X para manter o controle de qualidade das CCAs produzidas, pois que em situação de produção em larga escala, podem ser utilizadas cascas de origens diferentes.

Palavras-chave: Casca de arroz. Cinza de casca de arroz. Análise química. Difração de raios X.
Abstract
Rice production in Brazil in 2008 was approximately 12 million tons, and to achieve that amount several planting techniques were used with different strains of rice in different rice-growing areas. Since Rice Husk Ash (RHA) is the pozzolan of vegetable origin that is most studied by researchers working in the field of pozzolanic materials, this paper evaluates the influence that the form of planting, climate, soil, strain of rice and the origin/amount of nitrogen-based fertilizers used in rice cultivation have on the chemical composition and crystallographic properties of RHA. The results obtained in this study confirm the importance of carrying out routine chemical analysis and X-Ray diffraction to maintain the quality control of the CCAs produced because in situations of large-scale production, husks of different origins may be used.
Keywords: Rice husk. Rice husk ash. Chemical analisys. X-Ray diffraction. 


\section{Introdução}

Por definição, a casca de arroz é um revestimento ou capa protetora formada durante o crescimento do grão, de baixa densidade e elevado volume. É um material fibroso, cujos maiores constituintes são celulose $(50 \%)$, lignina $(30 \%)$ e resíduos inorgânicos (20\%). O resíduo inorgânico contém, em média, de $95 \%$ a $98 \%$, em peso, de sílica, perfazendo de $13 \%$ a $29 \%$ do total da casca (HOUSTON, 1972).

Hwang e Chandra (2002, p. 198) apresentam análises elementares de amostras distintas de cascas de arroz (Tabela 1), em que se observam pequenas variações no que se refere às quantidades de carbono, hidrogênio, oxigênio, nitrogênio e cinza.

O resíduo inorgânico obtido após a queima da casca contém, em média, $90 \%$ de sílica, bem como óxidos de potássio, magnésio, sódio, cálcio, ferro, fósforo, manganês e alumínio (DELLA, 2005, p. 9).

Segundo Amick (1982), Della (2005) e Gava (1999), a composição química da CCA pode variar de acordo com a variedade da planta, o sistema de cultivo, as condições climáticas e geográficas, o ano de colheita, os teores e tipos de fertilizantes empregados na plantação, a preparação da amostra e os métodos de análise. Contudo, os trabalhos desenvolvidos por esses autores não tinham como objetivo principal a análise dessas variáveis na composição da cinza de casca de arroz. Poucos trabalhos na literatura foram realizados nesse sentido. Entre eles estão Thenabadu (1977) ${ }^{1}$ e Irri (1982) ${ }^{2}$ apud JULIANO, 1985, p. 697), que é uma nova edição de Houston (1972), referência muito utilizada pelos pesquisadores que trabalham com CCA.

Thenabadu (1977) fez um estudo da localização da sílica contida na casca de arroz de quatro cultivares plantadas em sete locais diferentes, que abrangiam três zonas climáticas distintas do Sri Lanka. O autor mostrou que houve diferença significativa na quantidade de sílica em cinco das sete localidades avaliadas.

Irri (1982) avaliou a influência das estações na quantidade de sílica presente na casca de arroz de 18 cultivares. De acordo com o autor, na estação seca, a quantidade de sílica encontrada em média foi de $18,6 \%$, enquanto na úmida foi de $15,4 \%$. Foi constatada essa tendência de comportamento em praticamente todos as cultivares.

\footnotetext{
${ }^{1}$ THENABADU, M. W. Silica content of rice rusk as determined by soil properties and varietal differences. Journal of Tropic Agriculture, v. 133, p. 71-80, 1977

2 IRRI. International Rice Research Institute. Annual Report, 1982.
}

Hunt, Dismukes e Amick (1984, p. 1684) avaliaram amostras de casca de arroz provenientes de diferentes partes do mundo buscando determinar se existem ou não diferenças significativas nas concentrações de impurezas. Os autores encontraram uma boa concordância entre os resultados obtidos. A Tabela 2 apresenta os resultados.

Nesse sentido, este trabalho visa contribuir com o conhecimento das diversas variáveis que compõem a produção da casca de arroz e suas consequiências nas características finais da CCA, que é um importante resíduo agroindustrial a ser utilizado como pozolana em argamassas e concretos. Recentemente, importantes trabalhos de notável relevância foram desenvolvidos com CCA no Brasil, como Tibone (2007), Silva (2007), Hoppe (2008) e Cordeiro (2009).

\section{Materiais}

A maioria das amostras de cascas de arroz para a análise das variáveis tipo de solo, clima, cultivares e fonte/quantidade de fertilizante foram originadas de uma pesquisa agronômica, cujo objetivo foi verificar a aplicação de doses tidas como elevadas (até $200 \mathrm{~kg}$ de nitrogênio por hectare). Foram avaliadas quatro doses de nitrogênio $(50,100,150$ e $200 \mathrm{~kg}_{\text {de }} \mathrm{N} \mathrm{ha}^{-1}$ ), aplicadas na semeadura ou em cobertura. Como fontes de nitrogênio foram utilizadas o Entec (com inibidor de nitrificação e enxofre em sua composição), sulfato de amônio e uréia. $\mathrm{O}$ experimento foi conduzido na Fazenda de Ensino e Pesquisa da FE-UNESP, Campus de Ilha Solteira, localizada no município de Selvíria, MS, em um latossolo vermelho distroférrico típico, anteriormente ocupado por vegetação de cerrado, com irrigação por aspersão na ocorrência de déficits hídricos.

Dentro desse grupo de amostras, foram adotadas algumas particulares para o desenvolvimento deste trabalho. São elas: sulfato de amônia $50 \mathrm{~kg}$ de N ha $^{-1}$; sulfato de amônia $200 \mathrm{~kg}$ de $\mathrm{N} \mathrm{ha}^{-1}$; uréia 50 $\mathrm{kg}$ de $\mathrm{N} \mathrm{ha}^{-1}$; uréia $200 \mathrm{~kg}$ de $\mathrm{N} \mathrm{ha}^{-1}$ e Entec $200 \mathrm{~kg}$ de $\mathrm{N} \mathrm{ha}^{-1}$. Todas essas amostras são do cultivar Curinga em virtude do seu comportamento mais homogêneo de produtividade.

Além dessas amostras, foram adotadas outras duas, de diferentes regiões do país, a fim de verificar as variáveis de clima, solo e outras cultivares. Uma delas é de origem da região de Dourados, MS, e a outra originada da região Nordeste do Brasil, mais especificamente do Maranhão. O Quadro 1 apresenta as características de cada casca de arroz utilizada nessa etapa do trabalho. 


\begin{tabular}{c|c|c|c|c|c|c}
\hline \multirow{2}{*}{ Amostra } & \multicolumn{6}{|c}{ Quantidade (\% em massa) } \\
\cline { 2 - 7 } & $\mathbf{C}$ & $\mathbf{H}$ & $\mathbf{O}$ & $\mathbf{N}$ & $\mathbf{S}$ & Cinza \\
\hline $\mathbf{1}$ & 38,3 & 5,7 & 39,8 & 0,5 & 0,0 & 15,5 \\
\hline $\mathbf{2}$ & 39,4 & 5,5 & 36,1 & 0,5 & 0,2 & 18,2 \\
\hline $\mathbf{3}$ & 39,5 & 5,5 & 37,7 & 0,8 & 0,0 & 16,5 \\
\hline
\end{tabular}

Fonte: Hwang e Chandra (2002, p. 198)

Tabela 1 - Análise de distintas cascas de arroz

\begin{tabular}{c|c|c|c|c|c}
\hline \multirow{2}{*}{$\begin{array}{c}\text { Impurezas } \\
\text { (parte por } \\
\text { milhão) }\end{array}$} & $\begin{array}{c}\text { Origem das cascas } \\
\text { (Arkansas) }\end{array}$ & Japão & $\begin{array}{c}\text { EUA } \\
\text { (Lousiana) }\end{array}$ & Malásia & Austrália \\
\hline $\mathbf{A l}$ & 20 & 10 & $2.000^{* *}$ & 10 & 10 \\
\hline $\mathbf{B}$ & 2 & 1 & 2 & 1 & 2 \\
\hline $\mathbf{C a}$ & 1.000 & 1.000 & 1.000 & 1.000 & 1.000 \\
\hline $\mathbf{F e}$ & 20 & 20 & $60^{* *}$ & 20 & 20 \\
\hline $\mathbf{K}$ & 4.000 & 8.000 & 2.000 & 1.200 & 3.800 \\
\hline $\mathbf{M g}$ & 900 & 200 & 600 & 300 & 500 \\
\hline $\mathbf{M n}$ & 500 & 200 & 500 & 200 & 350 \\
\hline $\mathbf{N a}$ & 20 & 50 & 10 & 20 & 25 \\
\hline $\mathbf{P}$ & $>1.000^{* *}$ & 200 & -- & 50 & 130 \\
\hline $\mathbf{S}$ & 50 & $>1.000^{* *}$ & -- & 20 & 40 \\
\hline $\mathbf{T i}$ & 2 & 0,5 & 10 & 1 & 3 \\
\hline
\end{tabular}

Obs.: seguidos de ${ }^{* *}$ podem ser atribuídos a problemas com a técnica analítica empregada

Fonte: Hunt, Dismukes e Amick (1984, p. 1684)

Tabela 2 - Amostras de diversas cascas de arroz ao redor do mundo

\begin{tabular}{|c|c|c|c|c|c|c|}
\hline Amostra & $\begin{array}{c}\text { Sistema } \\
\text { de cultivo }\end{array}$ & Clima & Cultivar & Solo & Fertilizante & $\begin{array}{c}\text { Quantidade } \\
\text { de } \\
\text { fertilizante }\end{array}$ \\
\hline SA 50 & $\begin{array}{l}\text { Terras } \\
\text { altas }\end{array}$ & $\begin{array}{l}\text { Tropical } \\
\text { úmido }\end{array}$ & Curinga & $\begin{array}{l}\text { Latossolo vermelho } \\
\text { distroférrico típico }\end{array}$ & $\begin{array}{l}\text { Fósforo, } \\
\text { potássio e } \\
\text { sulfato de } \\
\text { amônia }\end{array}$ & $50 \mathrm{~kg}$ de $\mathrm{N} \mathrm{ha}^{-1}$ \\
\hline SA 200 & $\begin{array}{l}\text { Terras } \\
\text { altas }\end{array}$ & $\begin{array}{l}\text { Tropical } \\
\text { úmido }\end{array}$ & Curinga & $\begin{array}{l}\text { Latossolo vermelho } \\
\text { distroférrico típico }\end{array}$ & $\begin{array}{l}\text { Fósforo, } \\
\text { potássio e } \\
\text { sulfato de } \\
\text { amônia }\end{array}$ & $200 \mathrm{~kg}$ de $\mathrm{N}^{-} a^{-}$ \\
\hline UR 50 & $\begin{array}{l}\text { Terras } \\
\text { altas }\end{array}$ & $\begin{array}{l}\text { Tropical } \\
\text { úmido }\end{array}$ & Curinga & $\begin{array}{l}\text { Latossolo vermelho } \\
\text { distroférrico típico }\end{array}$ & $\begin{array}{l}\text { Fósforo, } \\
\text { potássio e } \\
\text { uréia }\end{array}$ & $50 \mathrm{~kg}$ de $\mathrm{N} \mathrm{ha}^{-1}$ \\
\hline UR 200 & $\begin{array}{l}\text { Terras } \\
\text { altas }\end{array}$ & $\begin{array}{l}\text { Tropical } \\
\text { úmido }\end{array}$ & Curinga & $\begin{array}{l}\text { Latossolo vermelho } \\
\text { distroférrico típico }\end{array}$ & $\begin{array}{l}\text { Fósforo, } \\
\text { potássio e } \\
\text { uréia }\end{array}$ & $200 \mathrm{~kg}$ de $\mathrm{N} \mathrm{ha}^{-}$ \\
\hline ET 200 & $\begin{array}{l}\text { Terras } \\
\text { altas }\end{array}$ & $\begin{array}{l}\text { Tropical } \\
\text { úmido }\end{array}$ & Curinga & $\begin{array}{l}\text { Latossolo vermelho } \\
\text { distroférrico típico }\end{array}$ & $\begin{array}{l}\text { Fósforo, } \\
\text { potássio e } \\
\text { Entec }\end{array}$ & $200 \mathrm{~kg}$ de $\mathrm{N} \mathrm{ha}^{-}$ \\
\hline MA & $\begin{array}{l}\text { Terras } \\
\text { altas }\end{array}$ & $\begin{array}{l}\text { Semiárido } \\
\text { com chuvas }\end{array}$ & $\begin{array}{c}\text { Possíveis: } \\
\text { Aimoré, Bonança, } \\
\text { Colosso, } \\
\text { Primavera, } \\
\text { Talento, Caiapó, } \\
\text { Canastra, Carajás } \\
\text { e Carisma }\end{array}$ & Latossolo & $\begin{array}{l}\text { Fósforo e } \\
\text { potássio }\end{array}$ & - \\
\hline MS & $\begin{array}{l}\text { Terras } \\
\text { altas }\end{array}$ & $\begin{array}{l}\text { Temperado } \\
\text { úmido }\end{array}$ & $\begin{array}{c}\text { Possíveis: } \\
\text { Aimoré, } \\
\text { Primavera, } \\
\text { Caiapó, Carajás, } \\
\text { Carisma e } \\
\text { Maravilha } \\
\end{array}$ & Latossolo & $\begin{array}{l}\text { Fósforo e } \\
\text { potássio }\end{array}$ & - \\
\hline
\end{tabular}

Quadro 1 - Amostras de cascas de arroz 
Observa-se que a riqueza dos dados das amostras obtidas junto ao trabalho agronômico é maior em relação às amostras MS e MA. Isso aconteceu em virtude da dificuldade de se conseguirem dados sobre a origem das cascas nas beneficiadoras onde elas foram coletadas.

\section{Programa experimental}

A primeira etapa realizada foi acompanhar a colheita da planta de arroz na fazenda da agronomia da UNESP e coletar a amostra do Estado do Maranhão e a da Região de Dourados, Mato Grosso do Sul.

Após a colheita, o arroz foi submetido aos processos de trilhagem e beneficiamento, para posterior aproveitamento das cascas (Figura 1).

Com a aquisição das amostras de casca de arroz, elas passaram por um processo de lavagem, a fim de constatar possíveis impurezas. Para tanto, foi utilizada água deionizada purificada por osmose reversa (Figura 2).

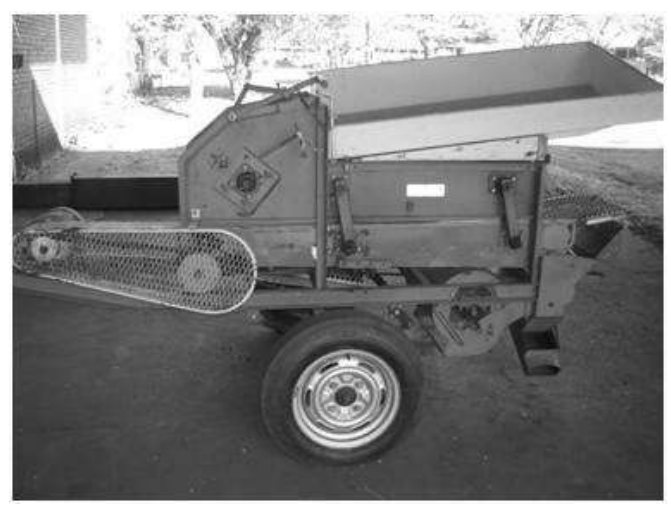

Essa lavagem foi feita de forma manual, em uma proporção em volume de 2 de água para 3 de casca. Após a mistura manual com espátula por 5 min, a água de lavagem foi peneirada e filtrada em papel-filtro. Depois disso, evaporaram-se as águas de lavagem até a secagem, que, em seguida foram levadas a uma mufla e calcinadas a $650{ }^{\circ} \mathrm{C}$ por $4 \mathrm{~h}$.

Para a calcinação das amostras de cascas de arroz, o sistema de queima utilizado foi a mufla com o controle de temperatura, taxa de aquecimento e patamar de temperatura para que as condições de queima fossem exatamente as mesmas para todas as amostras de casca de arroz.

Buscou-se, através desse sistema de queima, obter CCAs amorfas e com baixo teor de carbono, ou seja, características que favorecessem sua utilização como pozolana em argamassas e concretos. Para tanto, testes em mufla (Figura 3) foram realizados no sentido de determinar qual o procedimento de queima ótimo. Avaliou-se o tempo e patamar de temperatura ótima, taxa de aquecimento, perda de massa e propriedade cristalográfica.

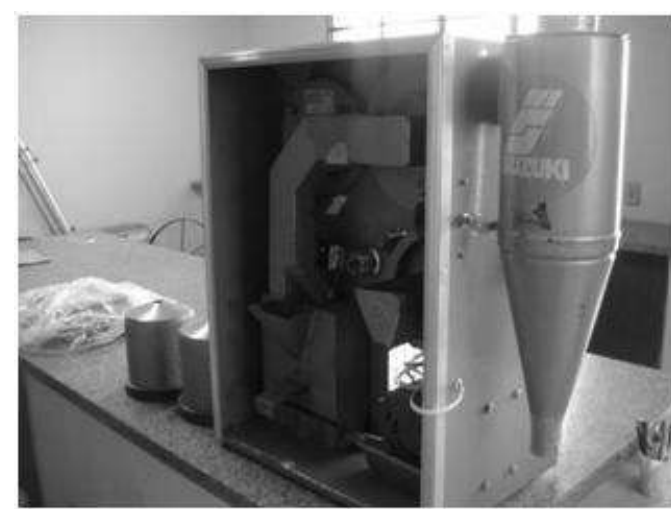

Figura 1 - Máquina de trilhagem e máquina de beneficiamento de arroz
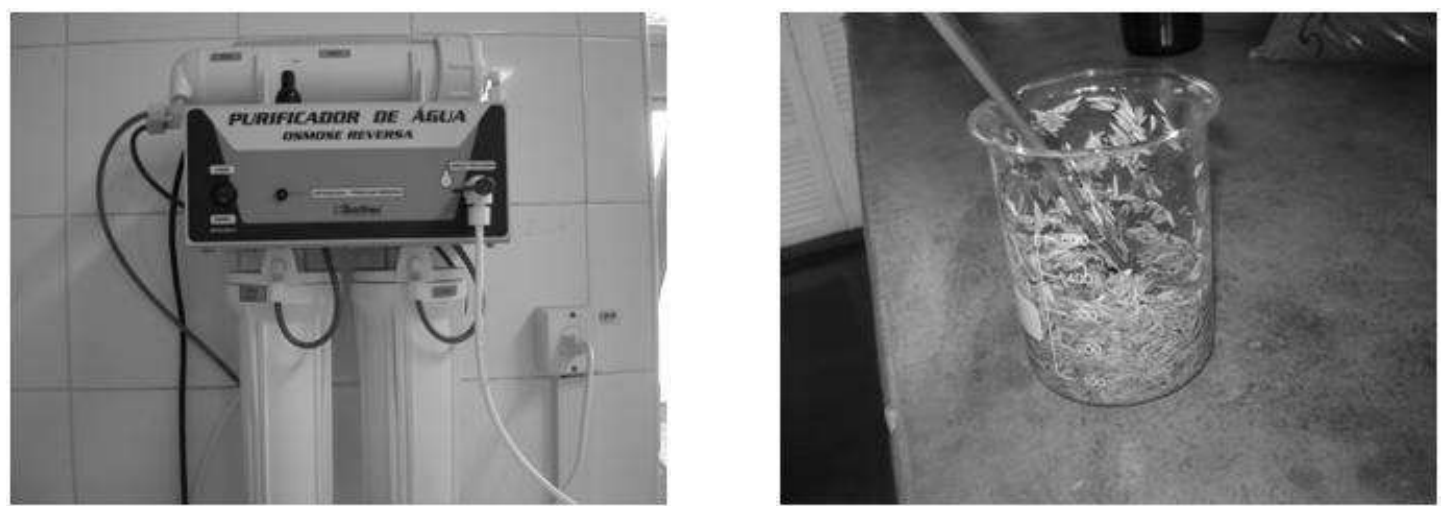

Figura 2 - Purificador de água e lavagem da casca 

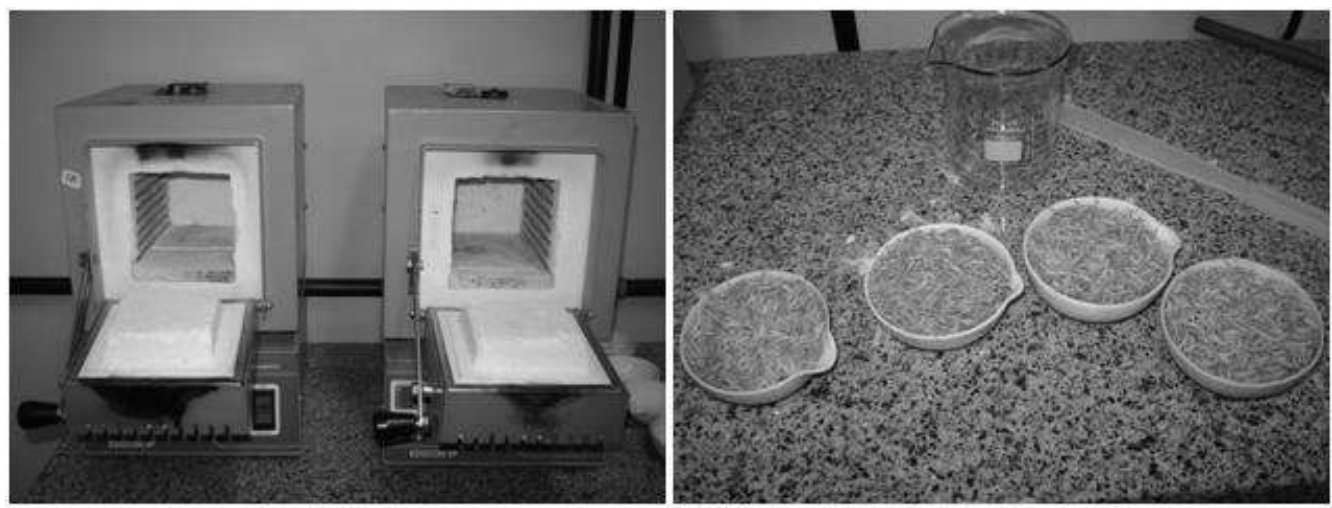

Figura 3 - Muflas utilizadas na calcinação e amostras de cascas de arroz

\begin{tabular}{lccccccccccc}
\hline Amostras & \multicolumn{1}{c}{$\mathrm{SiO}_{2}$} & $\mathrm{Al}_{2} \mathrm{O}_{3}$ & $\mathrm{Fe}_{2} \mathrm{O}_{3}$ & $\mathrm{CaO}$ & $\mathrm{Na}_{2} \mathrm{O}$ & $\mathrm{K}_{2} \mathrm{O}$ & $\mathrm{MnO}$ & $\mathrm{TiO}_{2}$ & $\mathrm{MgO}$ & $\mathrm{P}_{2} \mathrm{O}_{5}$ & $\mathrm{PF}^{*}$ \\
\hline CCA 1 & 72,10 & 0,30 & 0,15 & 0,43 & 0,05 & 0,72 & 0,15 & 0,05 & 0,70 & 0,06 & 24,30 \\
\hline CCA 4/1 & 89,75 & 0,68 & 0,21 & 0,50 & 0,16 & 0,92 & 0,15 & 0,01 & 0,86 & 0,71 & 6,05 \\
CCA 4/3 & 93,19 & 0,41 & 0,24 & 0,53 & 0,19 & 0,95 & 0,16 & 0,01 & 0,90 & 0,74 & 2,67 \\
\hline CCA 4/6 & 93,21 & 0,42 & 0,25 & 0,53 & 0,19 & 0,96 & 0,16 & 0,01 & 0,87 & 0,77 & 2,63 \\
\hline CCA 5/1 & 93,83 & 0,39 & 0,26 & 0,52 & 0,21 & 0,94 & 0,15 & 0,01 & 0,88 & 0,75 & 2,06 \\
\hline CCA 5/3 & 93,97 & 0,39 & 0,25 & 0,52 & 0,14 & 0,95 & 0,15 & 0,01 & 0,89 & 0,72 & 1,92 \\
CCA 5/6 & 93,95 & 0,45 & 0,26 & 0,51 & 0,20 & 0,94 & 0,15 & 0,01 & 0,89 & 0,72 & 1,92 \\
\hline CCA 6/1 & 94,09 & 0,38 & 0,26 & 0,53 & 0,17 & 0,94 & 0,16 & 0,01 & 0,88 & 0,77 & 1,82 \\
CCA 6/3 & 94,47 & 0,37 & 0,26 & 0,52 & 0,17 & 0,95 & 0,16 & 0,01 & 0,85 & 0,75 & 1,50 \\
\hline CCA 6/6 & 94,54 & 0,42 & 0,25 & 0,53 & 0,21 & 0,94 & 0,16 & 0,01 & 0,84 & 0,73 & 1,38 \\
CCA 7/1 & 94,58 & 0,55 & 0,28 & 0,54 & 0,24 & 0,96 & 0,17 & 0,02 & 0,88 & 0,73 & 1,05 \\
\hline CCA 7/3 & 94,67 & 0,41 & 0,26 & 0,58 & 0,25 & 0,95 & 0,17 & 0,02 & 0,91 & 0,81 & 0,97 \\
CCA 7/6 & 94,95 & 0,39 & 0,26 & 0,54 & 0,25 & 0,94 & 0,16 & 0,02 & 0,90 & 0,74 & 0,85 \\
\hline
\end{tabular}

Fonte: Della, Kuhn e Hotza (2005, p. 23)

Tabela 3 - Temperatura e tempo de calcinação

\begin{tabular}{c|c|c|c|c|c|l}
\hline Processo & $\begin{array}{c}\text { Temperatura } \\
\left({ }^{\mathbf{0}} \mathbf{C}\right)\end{array}$ & $\begin{array}{c}\text { Tempo } \\
(\mathbf{h})\end{array}$ & $\begin{array}{c}\text { Taxa de } \\
\text { aquecimento } \\
\left({ }^{\mathbf{0}} \mathbf{C} / \mathbf{m i n}\right)\end{array}$ & $\begin{array}{c}\text { Perda de } \\
\text { massa }(\boldsymbol{\%})\end{array}$ & Coloração & $\begin{array}{c}\text { Difração } \\
\text { de raios X }\end{array}$ \\
\hline 1 & 650 & 4 & 1 & 82,87 & Clara & Amorfa \\
\hline 2 & 650 & 4 & 5 & 82,45 & Clara & Amorfa \\
\hline 3 & 650 & 4 & 10 & 82,19 & Clara & Amorfa \\
\hline 4 & 650 & 4 & 15 & 82,00 & Clara & Amorfa \\
\hline
\end{tabular}

Tabela 4 - Estudo da taxa de aquecimento para calcinação

Della, Kuhn e Hotza (2005) fizeram diversas configurações de temperatura de queima/tempo de queima. Os autores trabalharam com CCA calcinada desde $400{ }^{\circ} \mathrm{C}$ até $700{ }^{\circ} \mathrm{C}$, com os tempos de 1 h, 3 h e 6 h, conforme a Tabela 3.

Os autores concluíram que o procedimento que confere uma sílica com maior grau de pureza é o da última linha, com $700{ }^{\circ} \mathrm{C}$ e tempo de $6 \mathrm{~h}$. Contudo, para este trabalho foi feita uma interpolação desses resultados e utilizou-se uma temperatura de queima de $650^{\circ} \mathrm{C}$ e tempo de $4 \mathrm{~h}$ para todas as amostras de casca de arroz, pois com essa configuração já se alcançam resultados satisfatórios (coloração clara e com arranjo molecular amorfo). Para este trabalho, a taxa de aquecimento também foi avaliada, conforme a Tabela 4.

Para a calcinação das amostras SA 50, SA 200, UR 50, UR 200, ET 200, MA e MS foi adotado o processo 4, visto que se obteve uma CCA com mesmas características em um procedimento mais rápido e econômico. A pequena variação da perda de massa se deve ao fato de a queima ser mais lenta para a taxa de aquecimento de $1^{\circ} \mathrm{C} / \mathrm{min}$. 
Com o procedimento ótimo determinado, todas as amostras de casca de arroz foram calcinadas e, posteriormente, moídas (manualmente, por meio de almofariz) para a realização dos ensaios de análise química por absorção de massa atômica e difração de raios X. É importante ressaltar que, para a realização dos ensaios nas CCAs, as amostras de cascas de arroz foram calcinadas sem o processo de lavagem, pois tal atividade poderia prejudicar a avaliação das influências estudadas para se alcançar o objetivo da pesquisa.

\section{Espectrofotômetro de absorção atômica}

O espectrofotômetro de absorção atômica foi utilizado para determinar quantitativamente os óxidos presentes em cada amostra de casca de arroz calcinada em mufla. A Figura 4 mostra o equipamento utilizado para a determinação desses óxidos.

\section{Difractômetro de Raios X}

A difração de raios $\mathrm{X}$ foi utilizada para a determinação da composição mineralógica das pozolanas em estudo. O difractômetro de raios $\mathrm{X}$ (Figura 5) foi empregado com radiação $\mathrm{K} \alpha$ de $\mathrm{Cu}$ e monocromador secundário (filtro de níquel), que elimina a radiação $K \beta$ de $\mathrm{Cu}$. A voltagem e a intensidade do tubo gerador de raios $\mathrm{X}$ foram ajustadas em $40 \mathrm{KV}$ e $20 \mathrm{~mA}$ respectivamente. As amostras foram ensaiadas em um suporte de alumínio, e os registros foram efetuados em um intervalo $2 \theta$ entre $5^{\circ}$ e $60^{\circ}$, com um intervalo de ângulo de $2 \theta$ de 0,02 e um tempo de acumulação de $2 \mathrm{~s}$.

\section{Resultados e discussões Águas de lavagem das cascas de arroz}

De acordo com Della et al. (2006, p. 1175), é importante que a casca de arroz passe por um processo de lavagem com água deionizada para a remoção de sujeiras superficiais (poeira e terra) e outros contaminantes possivelmente presentes.

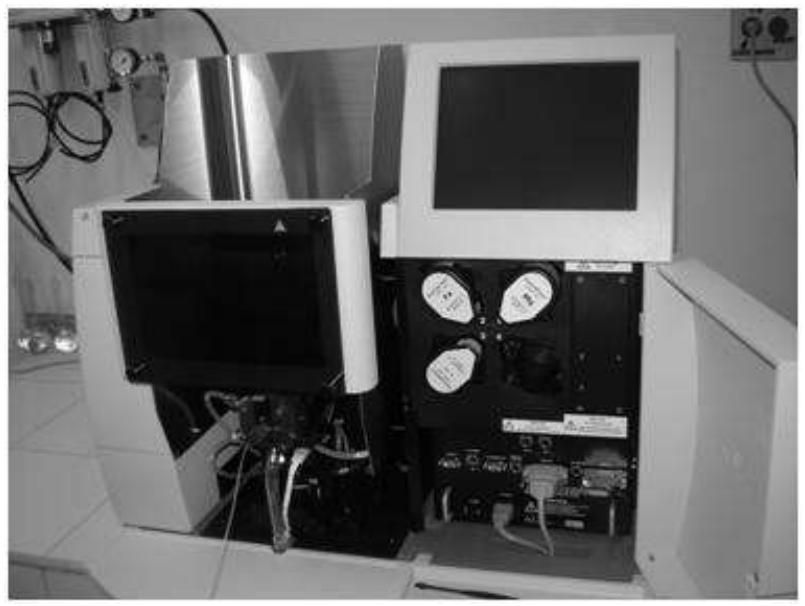

Figura 4 - Espectrosfotômetro de absorção atômica

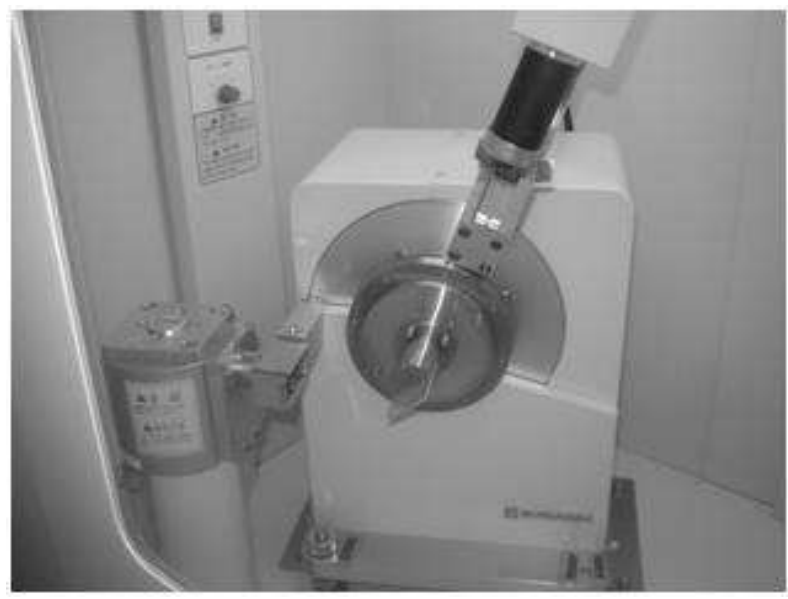


Após os tratamentos realizados na água de lavagem, observou-se que o resíduo resultante da água de lavagem da casca MA, apresentou coloração azulada bem mais acentuada que nas demais. Aos resíduos foi adicionado $\mathrm{HNO}_{3}$ diluído em água e, posteriormente, eles foram neutralizados com $\mathrm{NH}_{4} \mathrm{OH}$ diluído ao papel tornassol. $\mathrm{Na}$ neutralidade, parte do resíduo da amostra MA floculou de uma forma bem mais acentuada que nas outras amostras, o que pode ser indício da presença de materiais metálicos.

Della et al. (2006, p. 1178) afirmam que, em processos de lixívia ácida e lavagem, substâncias metálicas são dissociadas e posteriormente removidas. Sem a presença dessas substâncias, o carbono é liberado normalmente durante a calcinação, pois ele deixa de ser aprisionado dentro da fase líquida formada na superfície das partículas de cinza pela dissociação e posterior fusão dos óxidos metálicos fundentes (KRISHNARAO; SUBRAHMANYAM; KUMAR, 2001).

\section{Espectrofotômetro de absorção atômica}

Além das amostras descritas acima, calcinadas em mufla, também é apresentado o resultado das características químicas por absorção de massa atômica da amostra MS calcinada em um forno sem controle de temperatura (MS-Forno) e da amostra de CCA proveniente da empresa beneficiadora de arroz Josapar S.A., da região de Pelotas, RS, que já chegou calcinada. Para complementar, também foi feita análise química da amostra MA calcinada em forno.

A Tabela 5 apresenta o resultado das análises químicas de todas as amostras de CCA avaliadas. Fazendo uma análise geral dos resultados, observa- se que todas as amostras obtiveram o resultado de $\mathrm{SiO}_{2}+\mathrm{Al}_{2} \mathrm{O}_{3}+\mathrm{Fe}_{2} \mathrm{O}_{3}$ acima da quantidade mínima exigida pela NBR 12653 (ABNT, 1992), que é de $70 \%$, com todas as amostras acima de $90 \%$ desses constituintes, o que está de acordo com a literatura. Independentemente das variáveis envolvidas no processo, a quantidade de sílica presente na CCA é bastante elevada.

Com relação ao item perda ao fogo, uma das amostras, a RS, apresentou-se acima do limite máximo estipulado pela norma, que é $6 \%$. Isso é atribuído à maneira como a casca foi queimada (queima instantânea, que aprisiona o carbono devido à fusão de óxidos metálicos antes da oxidação do carbono). A amostra MA, que apresentou um resíduo azulado em sua água de lavagem após a evaporação, apresentou o segundo valor mais elevado, $4,31 \%$.

A Figura 6 compara a quantidade de sílica e a soma dos compostos $\mathrm{SiO}_{2}+\mathrm{Al}_{2} \mathrm{O}_{3}+\mathrm{Fe}_{2} \mathrm{O}_{3}$

A primeira análise a se fazer do gráfico é a diferença que existe na quantidade de sílica entre as amostras MS-Forno/MA-Forno e as MS/MA, em virtude da diferença entre os processos de calcinação utilizados. Tanto a MS quanto a MA, calcinadas em mufla, apresentam quantidades maiores de $\mathrm{SiO}_{2}, \mathrm{Al}_{2} \mathrm{O}_{3}$ e $\mathrm{Fe}_{2} \mathrm{O}_{3}$ que as calcinadas em forno, o que demonstra a influência na caracterização química de mesma amostra queimada em condições diferentes.

Analisando as mesmas amostras, mas fixando-se a variável tipo de queima, percebe-se que, embora sejam de regiões onde solo, clima, cultivar e fertilizantes empregados são diferentes, a diferença do teor de sílica foi pequena, independentemente da forma de queima.

\begin{tabular}{|c|c|c|c|c|c|c|c|c|c|c|c|c|c|}
\hline \multirow{2}{*}{\multicolumn{2}{|c|}{$\begin{array}{c}\text { Ensaios } \\
\text { Densidade } \\
\text { absoluta }\left(\mathrm{g} / \mathrm{cm}^{3}\right)\end{array}$}} & \multirow{2}{*}{$\begin{array}{c}\text { MS-Forno } \\
2,15\end{array}$} & \multirow{2}{*}{$\begin{array}{c}\text { MA- } \\
\text { Forno }\end{array}$} & \multirow{2}{*}{\begin{tabular}{l|}
$\boldsymbol{R S}$ \\
2,16 \\
\end{tabular}} & \multirow{2}{*}{$\begin{array}{l}M S \\
\mathrm{n} / \mathrm{d}\end{array}$} & \multirow{2}{*}{$\begin{array}{r}\boldsymbol{M A} \\
\mathrm{n} / \mathrm{d}\end{array}$} & \multirow{2}{*}{\begin{tabular}{c|} 
SA 50 \\
$\mathrm{n} / \mathrm{d}$
\end{tabular}} & \multirow{2}{*}{$\begin{array}{l}S A \\
200 \\
\mathrm{n} / \mathrm{d}\end{array}$} & \multirow{2}{*}{$\begin{array}{c}\boldsymbol{U R} 50 \\
\mathrm{n} / \mathrm{d}\end{array}$} & \multirow{2}{*}{$\begin{array}{l}\boldsymbol{U R} \\
200 \\
\mathrm{n} / \mathrm{d}\end{array}$} & \multirow{2}{*}{$\begin{array}{c}\boldsymbol{E T} \\
200 \\
\text { n/d }\end{array}$} & \multicolumn{2}{|c|}{$\begin{array}{c}\text { Especificações } \\
\text { NBR } 12653\end{array}$} \\
\hline & & & & & & & & & & & & mínimo & máximo \\
\hline \multirow{7}{*}{ 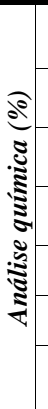 } & $\begin{array}{l}\text { Perda ao } \\
\text { fogo }\end{array}$ & 3,79 & 4,31 & 6,17 & 1,69 & 3,00 & 3,06 & 2,28 & 3,02 & 2,34 & 2,46 & - & 6 \\
\hline & $\mathrm{SiO}_{2}$ & 90,37 & 90,54 & 88,55 & 94,88 & 93,00 & 93,42 & 89,58 & 90,65 & 93,41 & 92,21 & - & - \\
\hline & $\mathrm{Fe}_{2} \mathrm{O}_{3}$ & 0,43 & 0,24 & 0,74 & 0,21 & 0,16 & 0,23 & 0,02 & 0,13 & 0,41 & 0,13 & - & - \\
\hline & $\mathrm{Al}_{2} \mathrm{O}_{3}$ & 0,12 & 0,13 & 1,74 & 0,31 & 0,52 & 0,22 & 0,58 & 0,25 & 0,15 & 0,37 & - & - \\
\hline & $\mathrm{CaO}$ & 1,25 & 0,04 & 1,11 & 0,14 & 0,04 & 0,04 & 0,04 & 0,04 & 1,34 & 0,04 & - & - \\
\hline & $\mathrm{MgO}$ & 0,27 & 0,20 & 0,32 & 0,20 & 0,20 & 0,33 & 0,36 & 0,40 & 0,33 & 0,40 & - & - \\
\hline & $\begin{array}{l}\mathrm{Al}_{2} \mathrm{O}_{3}+ \\
\mathrm{Fe}_{2} \mathrm{O}_{3}\end{array}$ & 0,55 & 0,38 & 2,45 & 0,52 & 0,68 & 0,45 & 0,60 & 0,38 & 0,56 & 0,50 & - & - \\
\hline
\end{tabular}




\begin{tabular}{c|c|r|r|r|r|r|r|r|r|r|c|c}
\hline $\begin{array}{c}\mathrm{SiO}_{2}+\mathrm{Al}_{2} \mathrm{O}_{3} \\
+\mathrm{Fe}_{2} \mathrm{O}_{3}\end{array}$ & 91,28 & 90,92 & 91,00 & 95,40 & 93,68 & 93,87 & 90,18 & 91,03 & 93,97 & 92,71 & 70 & - \\
\hline $\mathrm{Na}_{2} \mathrm{O}$ & 0,02 & 0,05 & 0,13 & 0,01 & 0,12 & 0,01 & 0,02 & 0,01 & 0,02 & 0,02 & - & - \\
\hline $\mathrm{K}_{2} \mathrm{O}$ & 0,48 & 1,08 & 0,36 & 0,24 & 0,60 & 0,48 & 0,68 & 0,13 & 0,48 & 0,48 & - & - \\
\hline $\begin{array}{c}\mathrm{E} . \mathrm{A} . \\
\left(\mathrm{Na}_{2} \mathrm{O}_{e q}\right)\end{array}$ & 0,16 & 0,77 & 0,37 & 0,17 & 0,52 & 0,33 & 0,50 & 0,10 & 0,33 & 0,34 & - & - \\
\hline
\end{tabular}

Tabela 5 - Resultado das análises químicas

A amostra RS apresentou a menor porcentagem de sílica entre todas as avaliadas. O fato de ter uma perda ao fogo mais elevada acaba diminuindo a quantidade de sílica percentual na CCA, o que, posteriormente, atrapalha sua reatividade sobre dois aspectos: menor quantidade de sílica para promover as reações pozolânicas e quantidade de carbono maior, o que exigirá mais água e/ou superplastificante em argamassas e concretos.

De acordo com os resultados observados nas amostras de CCAs originadas da pesquisa agronômica, nota-se que mesmo fixando as variáveis: solo, clima, cultivar e fertilizante empregado, pode haver diferença na quantidade de sílica presente na CCA. Verifica-se diferença de $3,83 \%$ de sílica nas amostras SA 50 e SA 200. Isso indica que a diferença de $150 \mathrm{~kg} / \mathrm{ha}$ de sulfato de amônio foi responsável por essa diferença.

No caso da ureia, a diferença entre as amostras UR 50 e UR 200 foi menor, $2,76 \%$, demonstrando que não há uma correlação diretamente proporcional entre a quantidade de fertilizante e sua influência no teor de sílica da CCA. A amostra ET 200 apresentou um valor mediano em comparação com as demais.

Ao comparar essas amostras da pesquisa agronômica com as MS e MA, quando todas as variáveis são diferentes, encontra-se uma variação de até $5,3 \%$ de sílica, confirmando os resultados encontrados na literatura (IRRI, 1982; THENABADU, 1977).

No que diz respeito às substâncias metálicas $\mathrm{Na}_{2} \mathrm{O}$ e $\mathrm{K}_{2} \mathrm{O}$, a Figura 7 apresenta o resultado.

A quantidade elevada na amostra MA-Forno explica sua coloração mais escura após a calcinação tanto em forno quanto em mufla. Isso indica que essa casca, de origem do Estado do Maranhão, apresenta uma condição diferente das demais, visto que, embora a quantidade de sílica não tenha sido afetada, o elevado teor de $\mathrm{Na}_{2} \mathrm{O}+$ $\mathrm{K}_{2} \mathrm{O}$ pode ter contribuído para deixar a CCA mais escura (Figura 7). Esse fato poderia inviabilizar sua utilização em virtude dos prejuízos estéticos, já que as demais amostras apresentaram-se com coloração clara, inclusive a MS-Forno, queimada no mesmo forno sem controle de temperatura. Embora a amostra SA 200 também tenha tido uma quantidade elevada dessas substâncias, sua coloração não foi prejudicada. A Figura 8 ilustra a influência de $\mathrm{Na}_{2} \mathrm{O}$ e $\mathrm{K}_{2} \mathrm{O}$ na perda ao fogo do material.

Desconsiderando a amostra RS, que foi calcinada instantaneamente, a MA-Forno, como o esperado, obteve a maior perda ao fogo. Isso é reflexo do elevado teor de $\mathrm{Na}_{2} \mathrm{O}+\mathrm{K}_{2} \mathrm{O}$, responsável pelo aprisionamento do carbono. $\mathrm{O}$ único caso que fugiu a essa regra foi a amostra UR 50, cuja perda ao fogo não foi pequena, embora com baixo teor de $\mathrm{Na}_{2} \mathrm{O}+\mathrm{K}_{2} \mathrm{O}$.

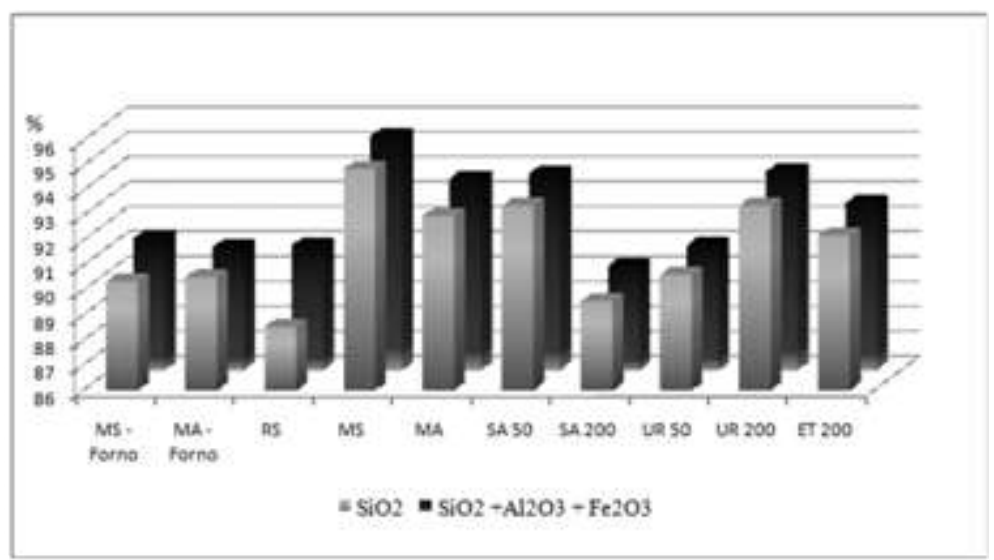

Figura 6 - Quantidade de $\mathrm{SiO}_{2}$ e $\mathrm{SiO}_{2}+\mathrm{Al}_{2} \mathrm{O}_{3}+\mathrm{Fe}_{2} \mathrm{O}_{3}$ 


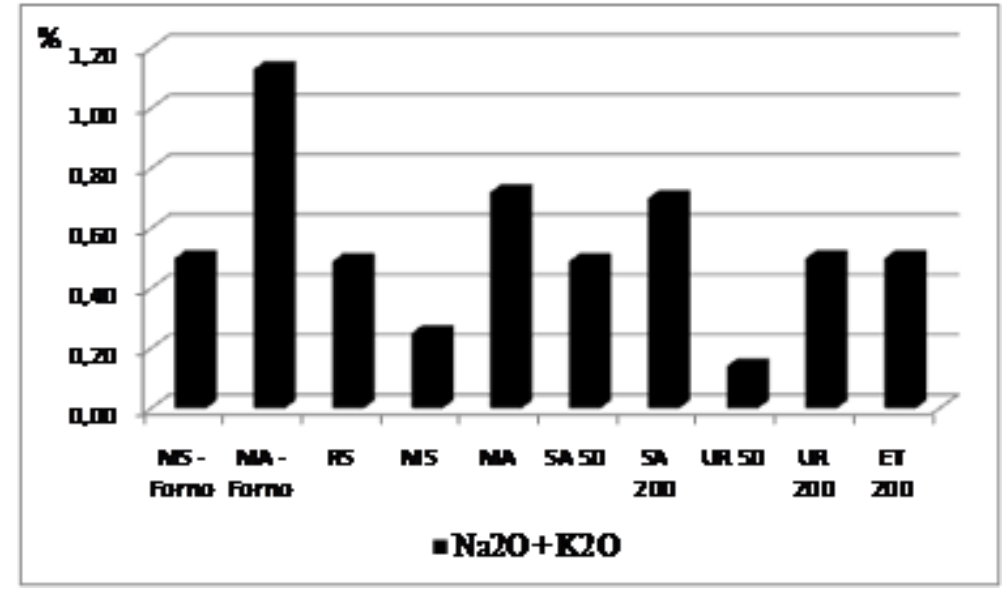

Figura 7 - Quantidade de $\mathrm{Na}_{2} \mathrm{O}+\mathrm{K}_{2} \mathrm{O}$

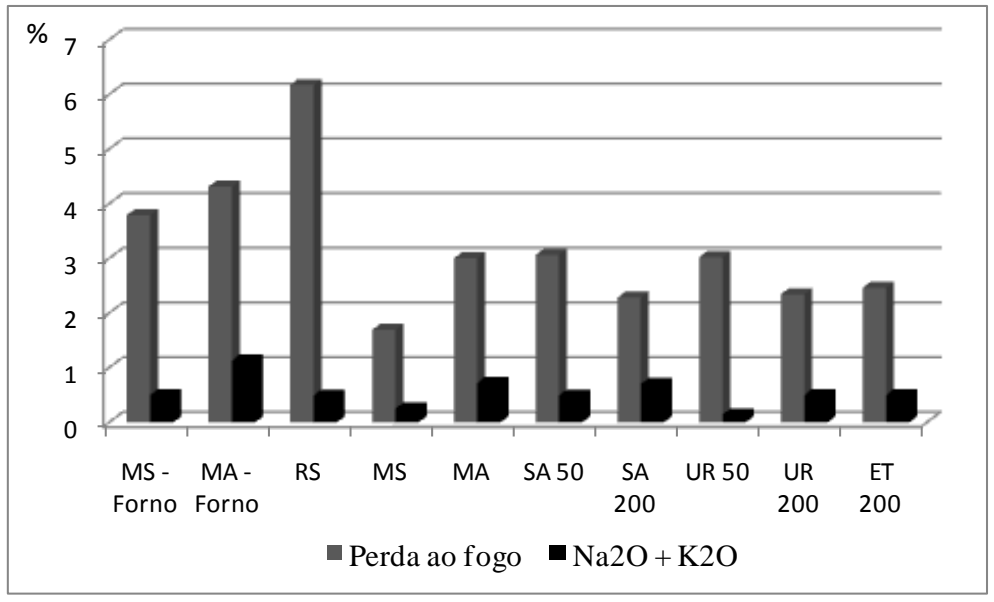

Figura 8 - Perda ao fogo e quantidade de $\mathrm{Na}_{2} \mathrm{O}+\mathrm{K}_{2} \mathrm{O}$

De uma maneira geral, percebe-se que as amostras da pesquisa agronômica obtiveram um desempenho semelhante quanto à porcentagem de $\mathrm{Na}_{2} \mathrm{O}+\mathrm{K}_{2} \mathrm{O}$ e perda ao fogo, o que indica que a variação de quantidade e fonte de fertilizantes empregados na cultura não influenciou de maneira expressiva nessas propriedades. Isso mostra que as outras variáveis como tipo de solo, clima e cultivares, principalmente na amostra do Estado do Maranhão, favoreceram a presença de $\mathrm{Na}_{2} \mathrm{O}+\mathrm{K}_{2} \mathrm{O}$ na CCA, que, por conseqüência, aumentou sua perda ao fogo.

Embora a perda ao fogo da amostra MA não tenha sido muito elevada, a Figura 9 apresenta a diferença entre as amostras MA (segunda linha, terceira coluna) e MA-Forno (terceira linha, primeira coluna). Todas as outras amostras apresentaram-se com uma coloração clara.

\section{Difração de Raios X}

No ensaio de difração de raios $\mathrm{X}$, constatou-se que a maioria das amostras calcinadas em mufla apresentou uma estrutura amorfa de sua sílica, o que mostra que, quando calcinadas em condições adequadas, mesmo CCAs com elevado teor de impurezas, podem apresentar estrutura amorfa. Verifica-se também que a variável tipo e fonte de fertilizante não afetou o teor de amorficidade das CCAs. As figuras a seguir apresentam os resultados do ensaio das amostras de origem da pesquisa agronômica.

Verifica-se nas Figuras 10 e 11 que as amostras UR 50 e 200 não apresentaram nenhum pico em seus resultados e que o desvio da linha-base entre os ângulos de 15 e 30 graus indica a amorficidade das amostras.

As Figuras 12 e 13 também descrevem trajetórias de material amorfo, porém na amostra SA 50 há um pico correspondente a quartzo. Esse pico foi observado apenas nesta amostra, o que pode ser sinal de alguma impureza externa que influenciou no resultado do ensaio. Pequenos picos de cristobalita e tridimita foram encontrados na amostra ET 200 (Figura 14), contudo se constata que eles não são suficientes para concluir que essa 
amostra, por ser adubada com o fertilizante Entec com $200 \mathrm{~kg} / \mathrm{ha}$, foi responsável pela formação desses picos. Além disso, verifica-se que o desvio da linha-base entre os ângulos de 15 e 30 está de acordo com as demais amostras amorfas.

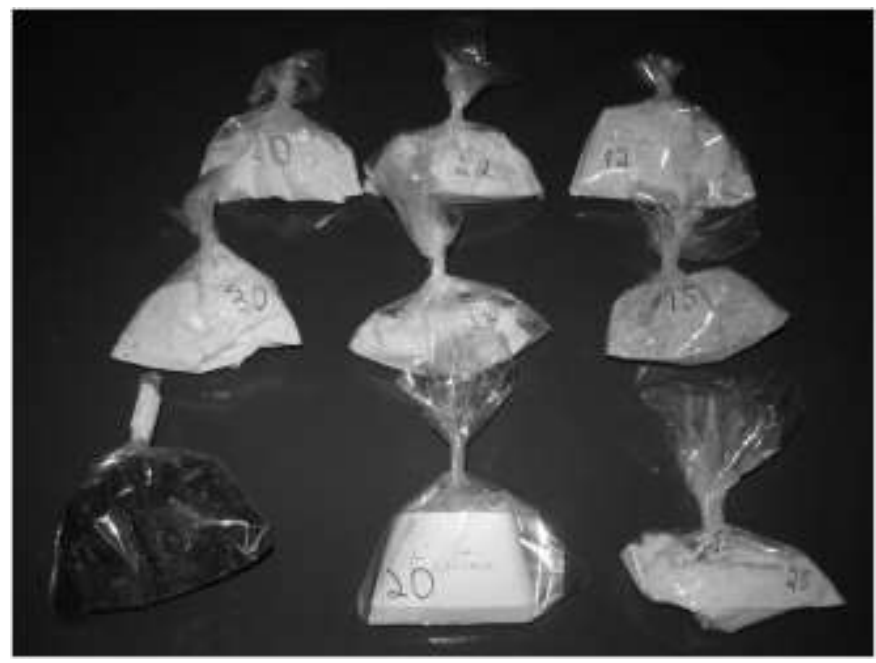

Figura 9 - Amostras das CCAs

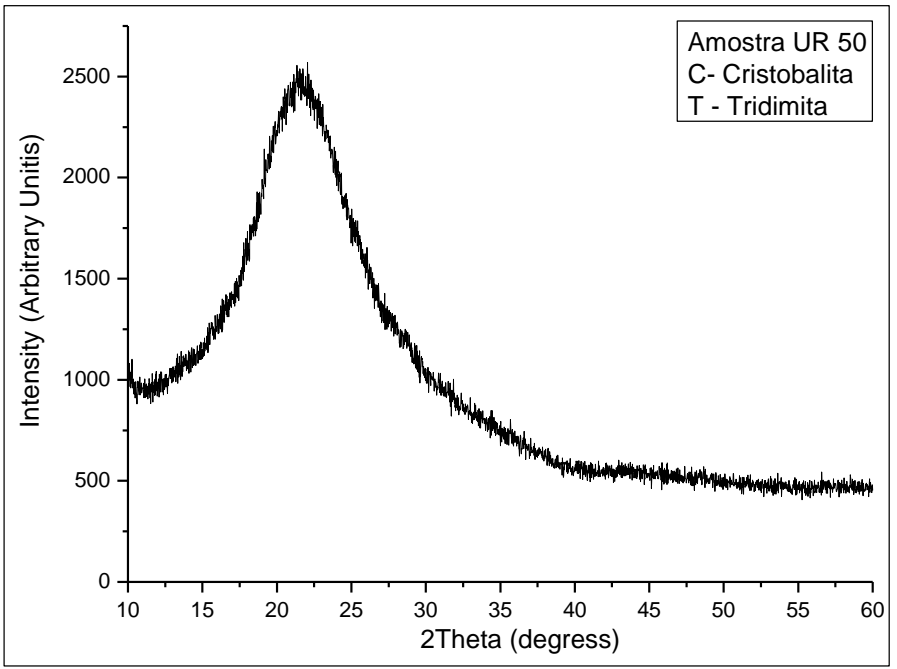

Figura 10 - Difratograma de raios $X$ da amostra UR 50 


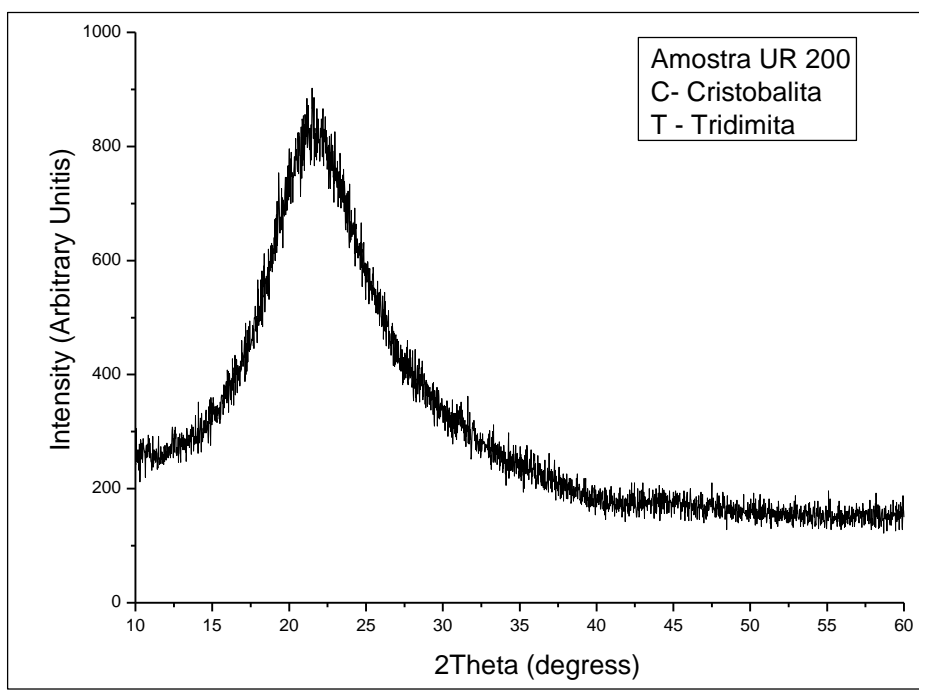

Figura 11 - Difratograma de raios X da amostra UR 200

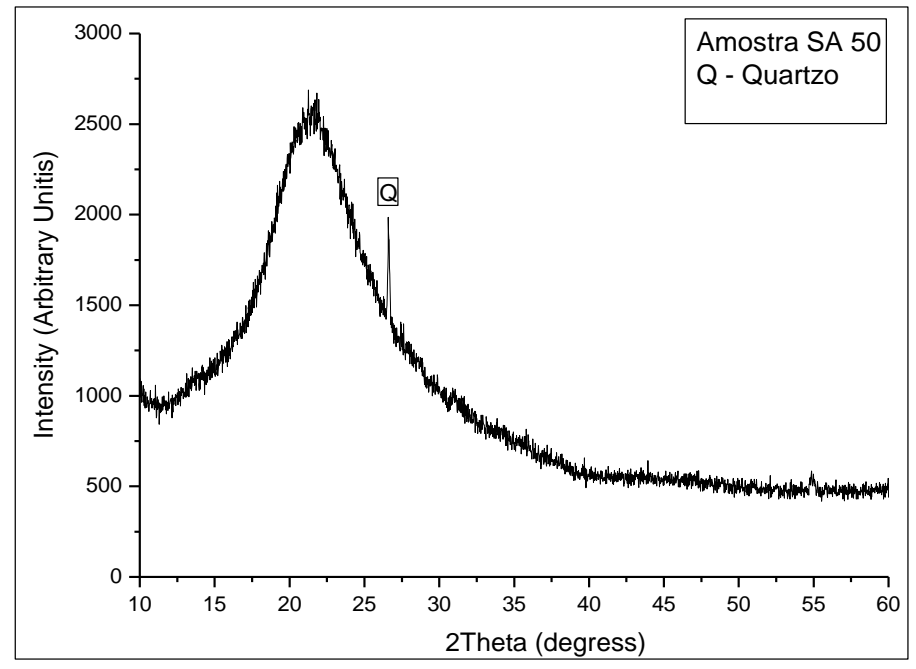

Figura 12 - Difratograma de raios $X$ da amostra SA 50 


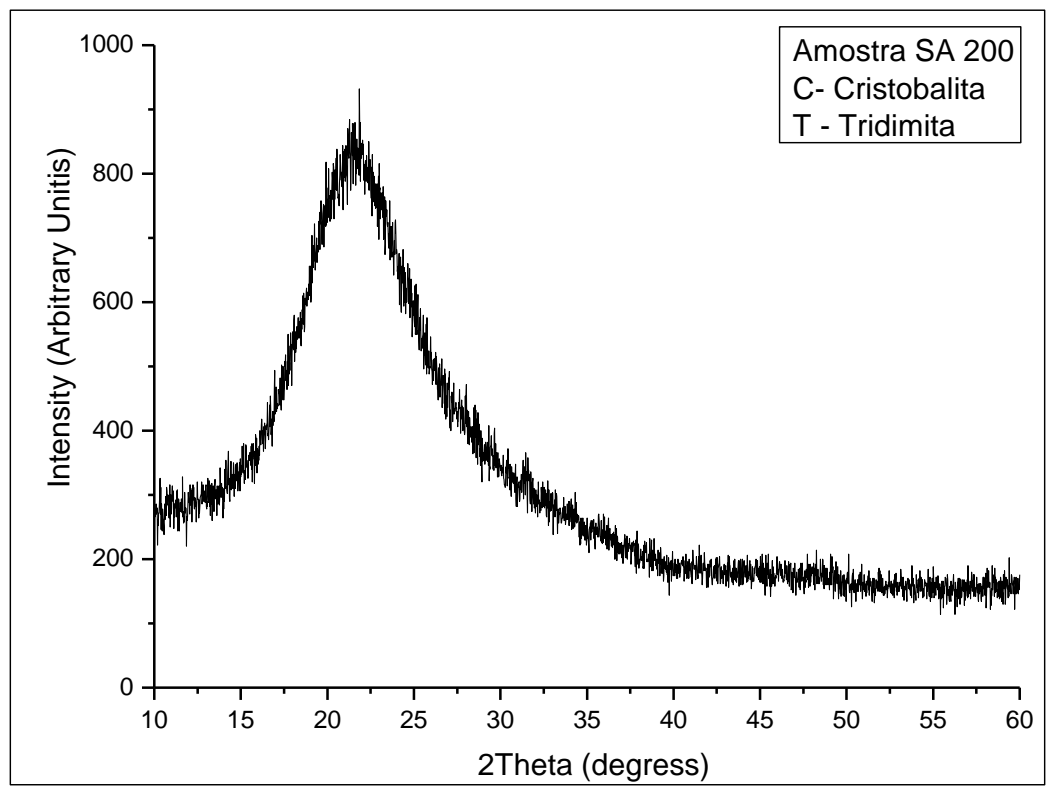

Figura 13 - Difratograma de raios X da amostra SA 200

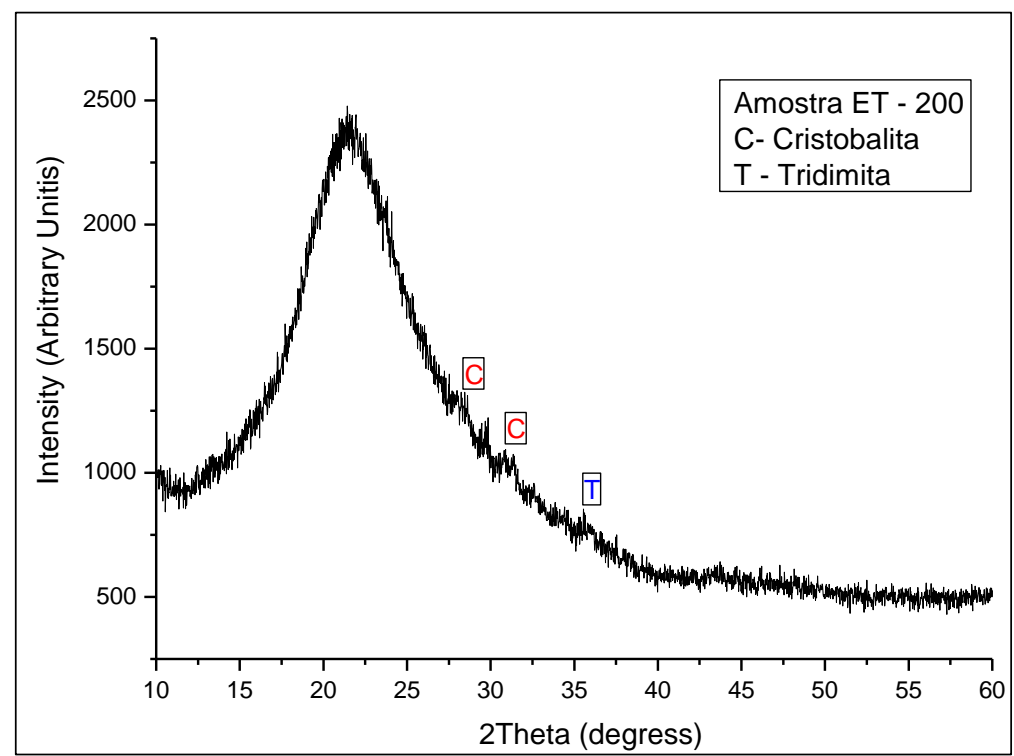

Figura 14 - Difratograma de raios X da amostra ET 200

O difratograma da amostra RS (Figura 15) indica um comportamento cristalino, verificado através dos picos de cristobalita e tridimita que revelam a cristalografia do material. Isso aconteceu em função da forma como a casca foi calcinada.

As Figuras 16 e 17 apresentam as amostras MS e MA queimadas em mufla. Verifica-se que a amostra MS é amorfa, assim como a MA; no entanto, nota-se um pico de cristobalita mais acentuado, em torno dos $23^{\circ}$ da amostra MA.

Analisando o comportamento dessas amostras de CCA, percebe-se pouca influência das variáveis tipo de solo, clima, cultivar e tipo/quantidade de fertilizantes empregados. Isso é atribuído à forma de queima, que é ideal para a eliminação de parte das impurezas, e à temperatura baixa de queima, que impediu a cristalização da CCA. 


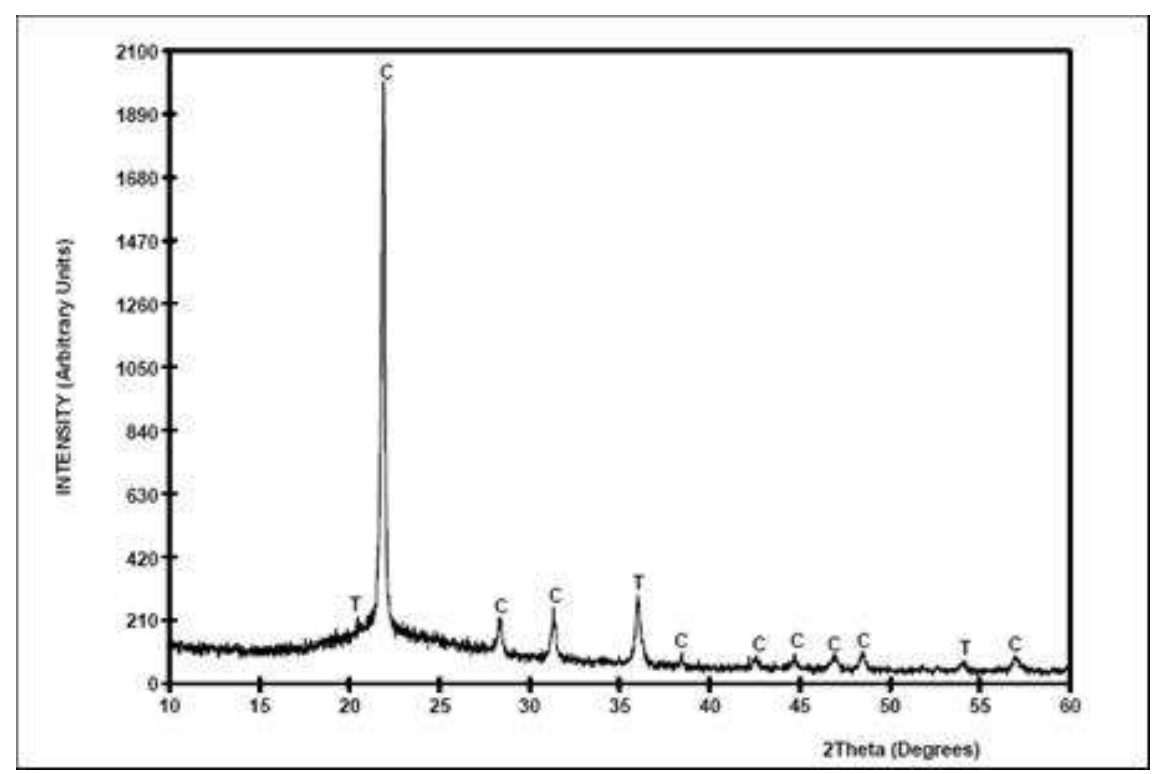

Figura 15 - Difratograma de raios $X$ da amostra RS

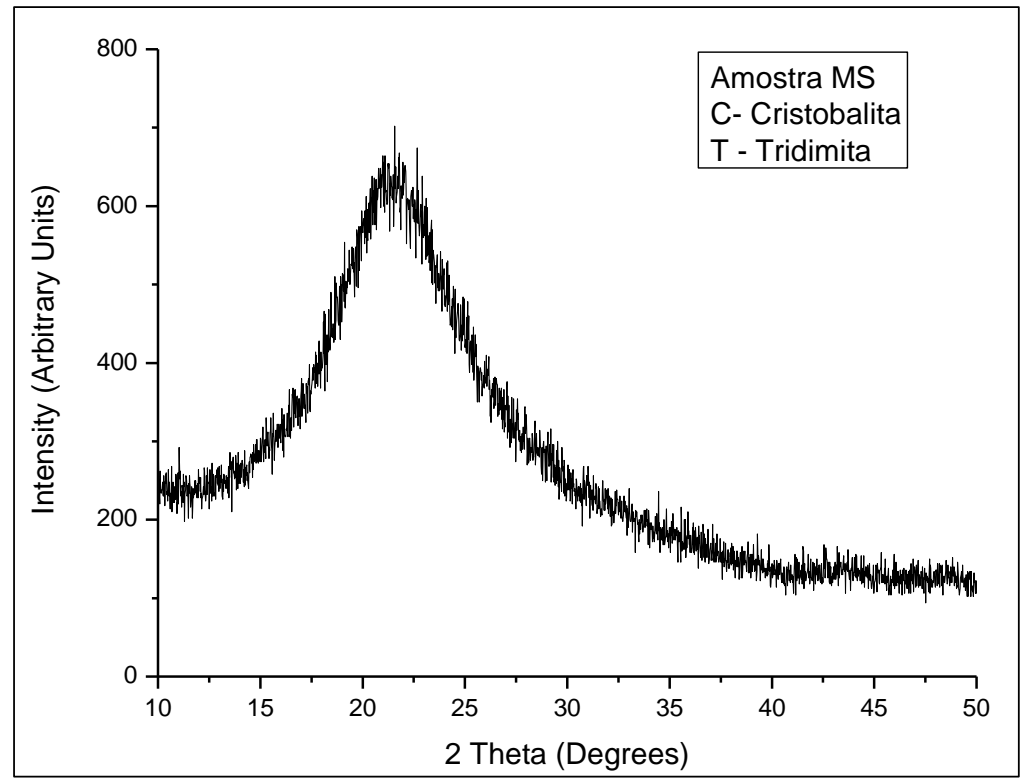

Figura 16 - Difratograma de raios $X$ da amostra MS 


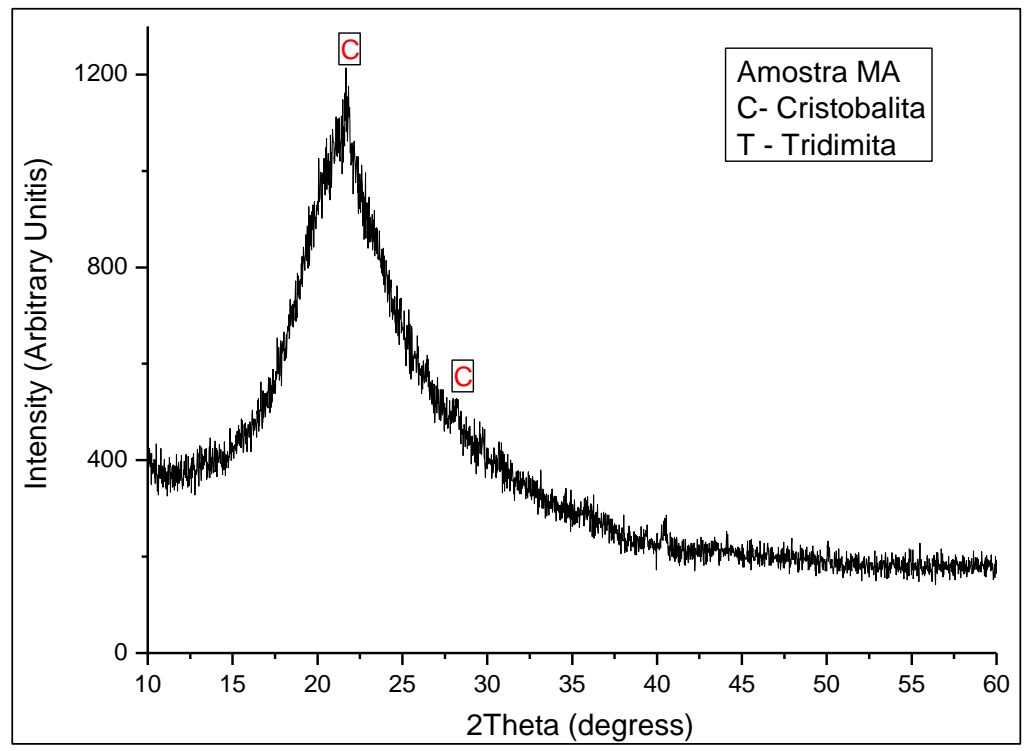

Figura 17 - Difratograma de raios $X$ da amostra $M A$

Em relação às amostras MS-Forno e MA-Forno, observaram-se comportamentos diferentes nas Figuras 18 e 19.

Enquanto a amostra MS-Forno apresenta-se amorfa, apenas com um pequeno pico de cristobalita, a MA-Forno possui muitos picos de tridimita e cristobalita. Como a temperatura do forno atinge $850{ }^{\circ} \mathrm{C}$ e permanece nesse patamar acima de $16 \mathrm{~h}$, possivelmente as substâncias metálicas em excesso presentes na amostra MAForno aceleraram o processo de cristalização da sílica (KRISHNARAO; SUBRAHMANYAM; KUMAR, 2001). Além disso, acredita-se na menor cristalização da MS-Forno devido ao maior teor de $\mathrm{CaO}$ em relação à MA-Forno, conforme a Tabela 5. O $\mathrm{CaO}$ é um poderoso agente de vitrificação utilizado na fabricação de vidro comum.

A Figura 17 já apresentava indícios (pico de cristobalita em torno de $23^{\circ}$ ) de que a sílica contida na amostra MA poderia cristalizar-se mais facilmente que as outras amostras, caso a temperatura de calcinação aumentasse.

\section{Conclusões}

Por meio deste trabalho, é possível concluir que todas as variáveis abordadas (forma de plantio, clima, solo, cultivares e fonte/quantidade de fertilizantes à base de nitrogênio) exercem influência na quantidade de sílica, presença de materiais metálicos e perda ao fogo da CCA.

No que diz respeito à propriedade cristalográfica, pode-se concluir que a variável fonte/quantidade de fertilizante empregado não exerceu influência significativa. No entanto, foi constatada em uma das amostras de CCA (MA) avaliadas uma forte tendência para cristalização da sílica, enquanto a amostra MS, submetida ao mesmo processo de calcinação sem controle de temperatura, apresentou-se amorfa. A partir daí, verifica-se a importância de se fazerem ensaios rotineiros de análises químicas e de difração de raios $\mathrm{X}$ para manter o controle de qualidade das CCAs produzidas, pois, em situação de produção de CCA em larga escala, podem ser utilizadas cascas de origens diferentes.

Além disso, conclui-se que a abordagem das variáveis envolvidas no plantio do arroz pode enriquecer a discussão e a compreensão dos resultados de pesquisas que tratam do aproveitamento da CCA na construção civil 


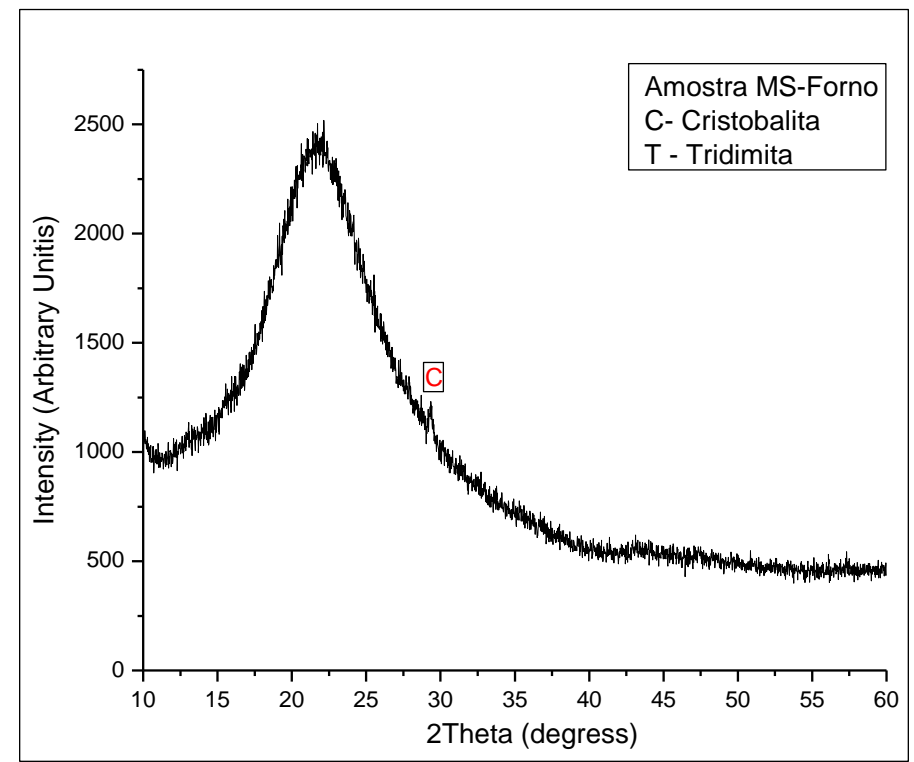

Figura 18 - Difratograma de raios X da amostra MS-Forno

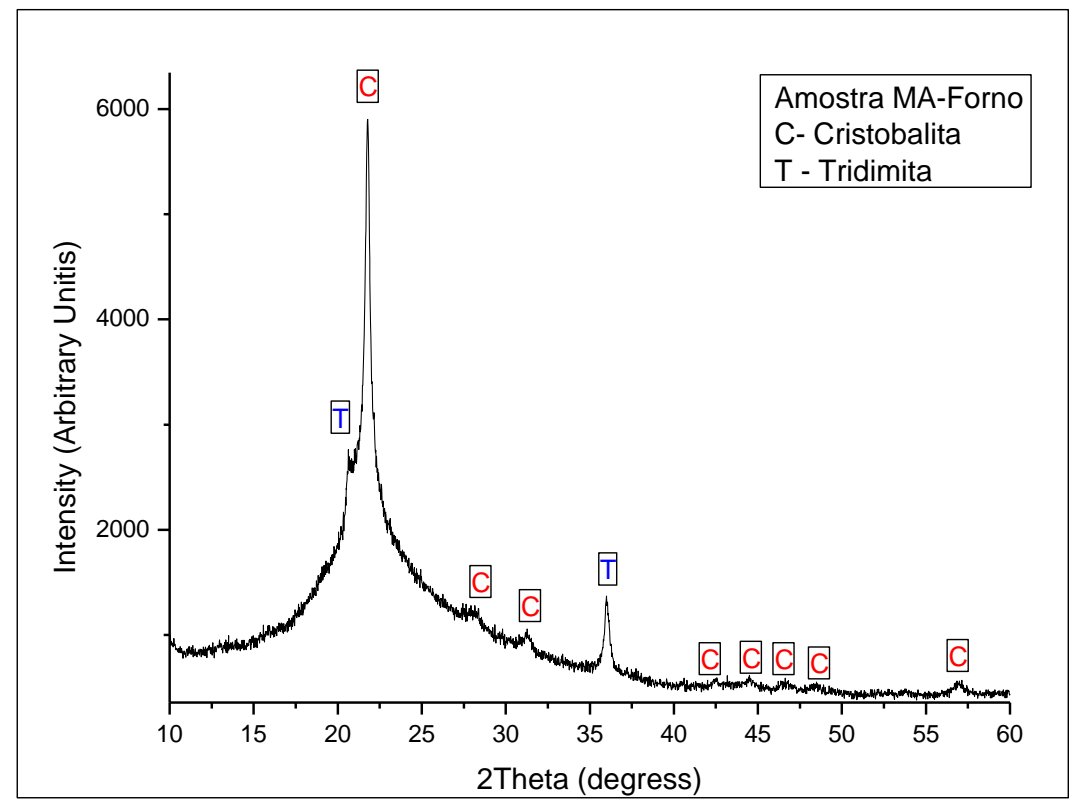

Figura 19 - Difratograma de raios X da amostra MA-Forno

\section{Referências}

AMICK, J. A. Purificacion of Rice Hulls as a Source of Solar Grade Silicon for Solar Cells. Journal of the Electronchemical Society, Nova Jersey, v. 129, n. 1, p. 864-866, 1982.

ASSOCIAÇÃO BRASILEIRA DE NORMAS

TÉCNICAS. NBR 12653: materiais pozolânicos: especificação. Rio de Janeiro, 1992. 3 p.
CORDEIRO, L. N. P. Análise da Variação do Índice de Amorfismo da Cinza de Casca de Arroz Sobre a Atividade Pozolânica. 2009. 98 f. Dissertação (Mestrado em Engenharia) - Escola de Engenharia Civil, Universidade Federal do Rio Grande do Sul, Porto Alegre, 2009. 
DELLA, V. P. Síntese e Caracterização do Pigmento Cerâmico de Hematita, Obtida a partir de Carepa de Aço, Encapsulada em Sílica Amorfa Obtida a partir da Casca de Arroz. 2005. 9 f. Tese (Doutorado em Engenharia de Materiais) - Faculdade de Ciência e Engenharia dos Materiais, Universidade Federal de Santa Catarina, Florianópolis, 2005.

DELLA, V. P.; KUHN, I.; HOTZA, D.

Reciclagem de Resíduos Agroindustriais: cinza de casca de arroz como fonte alternativa de sílica. Cerâmica Industrial, São Paulo, v. 10, n. 2, p. 22-25, 2005.

DELLA, V. P. et al. Estudo Comparativo entre Sílica Obtida por Lixívia Ácida da Casca de Arroz e Sílica Obtida por Tratamento Térmico da Cinza de Casca de Arroz. Química Nova, São Paulo, v. 29, n. 6, p. 1175-1179, 2006.

GAVA, G. P. Estudo Comparativo de Diferentes Metodologias para a Avaliação da Atividade Pozolânica. 1999. 118 f. Dissertação (Mestrado em Engenharia Civil) - Curso de pós-graduação em Engenharia Civil, Universidade Federal de Santa Catarina, Florianópolis, 1999.

HWANG, C. L., CHANDRA, S. The use of Rice Husk Ash in Concrete. In: CHANDRA, S. (Ed.). Waste Materials Used in Concrete

Manufacturing. Nova Delhi: Standard Publishers, 2002. p. 184-234.

HOPPE, A. E. Carbonatação em Concreto com Cinza de Casca de Arroz sem Moagem. 2008. 147 f. Dissertação (Mestrado em engenharia Civil) - Curso de Pós-Graduação em Engenharia Civil, Universidade Federal de Santa Maria, Santa Maria, 2008.

HOUSTON, D. F. Rice hulls, Rice Chemistry and Technology. Minnessota: American Association of Cereal Chemistry, 1972. p. 301352.
HUNT, L. P.; DISMUKES, J. P.; AMICK, J. A. Rice Hulls as a Raw Material for Producing Silicon. Mnos Structures, Novaw Jersey, v.131, n. 7, p. 168, 1984.

IRRI. Annual report for 1982. Int. Rice Res. Inst., Los Baños, Laguna, Philippines, 1982.

KRISHNARAO, R. V.; SUBRAHMANYAM, J.; KUMAR, T. J. Studies on the Formation of Black Particles in Rice Husk Ash. Journal of the European Ceramic Society, Grã Bretanha, v. 21, n. 1, p. 99-104, 2001.

JULIANO, O. B. Rice Hull and Straw. In: Rice: chemistry and tecnology. 2th. 1985. p. 697.

SILVA, I. O. Influência da Cinza de Casca de Arroz Amorfa e Cristalina e da Sílica Ativa na Reação Álcali-Agregado. 2007. 125 f.

Dissertação (Mestrado em Engenharia Civil) Escola de Engenharia Civil, Universidade Federal de Goiás, Goiânia, 2007.

THENABADU, M. W. Silica content of rice rusk as determined by soil properties and varietal differences. Trop. Agric. 133: 71-80, 1977.

TIBONE, R. A Utilização de Cinza de Casca de Arroz de Termoelétrica como Componente do Aglomerante de Compósitos à Base de Cimento Portland. 2007. 139 f. Dissertação (Mestrado em Engenharia Civil) - Escola de Engenharia de São Carlos, Universidade de São Paulo, São Carlos, 2007.

\section{Agradecimentos}

À Coordenação de Aperfeiçoamento de Pessoal de Nível Superior (CAPES); ao Laboratório CESP de Engenharia Civil; aos Laboratórios de Engenharia Civil, Física e Química da UNESP; às empresas fornecedoras de materiais; e aos professores doutores Salatiér Buzetti, Orivaldo Arf e Marcelo Ornaghi Orlandi. 